\title{
Formalization of Medical Guidelines
}

\section{Jan Peleška1', Zdeněk Anger², David Buchtela1', Karel Šebesta³, Marie Tomečková1, Arnošt Veselý1, Karel Zvára³, Jana Zvárová1}

1. Department of Medical Informatics, Institute of Computer Science AS CR, Prague, Czech Republic,

2. 2nd Dept.of Medicine, General University Hospital,

3. EuroMISE s.r.o.

\section{Summary:}

Formalization of medical guidelines by means of a general GLIF graphic model is demonstrated in the formalized 2003 European Guidelines on Cardiovascular Disease Prevention and 2003 ESH/ESC Hypertension Guidelines. It leads a user through the decision algorithm in diagnostics of several diseases, total cardiovascular risk estimation and appropriate treatment. Moreover, it can show both the basic information and the appropriate part of guidelines $(\mathrm{GL})$ complete text concerning the selected GLIF model element. The formalization of GL can function as a feedback for authors to remove uncertainties and information inconsistencies in GL. Estimation of the total cardiovascular risk and selection of a drug class is easier compared to a time consuming manipulation with tables of paper guidelines. It offers to physicians a system for a decision support and it checks their decision algorithms in comparison with those of GL. It could serve as a tool for an audit of physicians work by their professional society using the automatic system, preferably with a direct data access from a structured electronic health record in future. Computer GL presentation has the potential for an easier GL knowledge implementation than the classical paper GL form and thus to improve the primary care of cardiovascular diseases.

Keywords: GLIF model, formalization of guidelines, prevention of cardiovascular diseases

\section{Introduction}

Primary care faces the problem of increasing and quickly changing knowledge in the field of preventive cardiology. Recent surveys have shown that in the vast majority of cases methodological standards were not complied with guidelines (GL). Therefore, the new methods for better knowledge implementation of the joint 2003 European Guidelines on Cardiovascular Disease Prevention in Clinical Practice (CDPGL) in primary care are mandatory. The main point is to learn the quickly updated correct decision algorithm in diagnostics of several diseases, total cardiovascular disease (CVD) risk estimation using the SCORE Model and appropriate treatment given by the CDPGL [1], [2]. It seems to be useful to add some more detailed essential information about the management (mainly treatment) of associated risk factors such as hypertension, dyslipidemia and diabetes mellitus. This means to add not overlapping parts of appropriate guidelines for management of mentioned diseases, e.g. 2003 ESH/ESC Hypertension Guidelines (HGL) [3]. Computer GL presentation has the potential for an easier GL knowledge implementation than the classical paper GL form and thus to improve primary care.

\section{Materials and Methods}

The essential presumption to work with medical guidelines $(\mathrm{GL})$ on computer is their formalization that means their transformation to a structured form the computer can work with. Medical guidelines usually consist of diagnostic and therapeutical procedures for individual diseases or groups of diseases. Diagnostic and therapeutical procedures are usually given in a free text, in a better case partially as a flow chart, which in fact presents a way of text formalization of GL paper form. Generally, a formalization process means transcription of relations, processes, conditions and time relations by means of formal tools (e.g. logical formulae).

The most important and nowadays mostly used tool for a formalization is the GLIF (Guideline Interchange Format) model [4], [5], [6]. We use this GLIF model in two versions. The first one is educational and the other one (processing) enables suggestion of partial steps according GL linked to the information about patient either by direct input or from electronic health record (EHR).

We have created two separate systems. Educational version of $\mathrm{GL}$ is portable and is designed to be lightweight. Processing version of $\mathrm{GL}$ is designed for guidelines verification on a sample or real-life patient data.

Educational version of GL presentation system was designed to meet the following criteria:

- Internet distribution.

- Possibility of off line browsing (files can be downloaded and then viewed off line).

- Easy modifications and adaptability to various guidelines.

- Possibility of combination of HTML text, GLIF model graphs and specialized presentation modules where standard GLIF model presentation would be too complex. 
We developed several Java applet modules used to show guidelines graphically.

- Glifview is a GLIF model browser that can present any formalized medical guidelines in a user-friendly manner.

- Risk calculator is used to calculate cardiovascular risk and show it graphically.

- Drugs selection module is used to manage indications and contraindications for drug classes and selection of rational drug therapy.

All modules are universal with all presented data stored in XML files, so they can be easily adapted to various guidelines.

Processing version of $\mathrm{GL}$ has the following properties:

- Internet distribution.

- All data are stored in mySQL tables.

- After entering data defined parameters are calculated.

- Processing of GL is performed during their displaying using Macromedia Flash technology.

- Processing of GL starts from a chosen input step.

- For each step processing GL check all conditions (strict in, strict out, rule in, rule out, see [6], [7]) and verify the explicit further step. In case of the explicit further step it is processed. Otherwise the GL processing is stopped.

\section{Results}

The educational version of GL using the GLIF model leads a physician through the decision tree usually with yes-no alternatives in dependence on the physician's knowledge of patient's data. If a value of some variable is not available the physician can continue and simulate both possible alternatives at the concerned decision step (Figure 1).

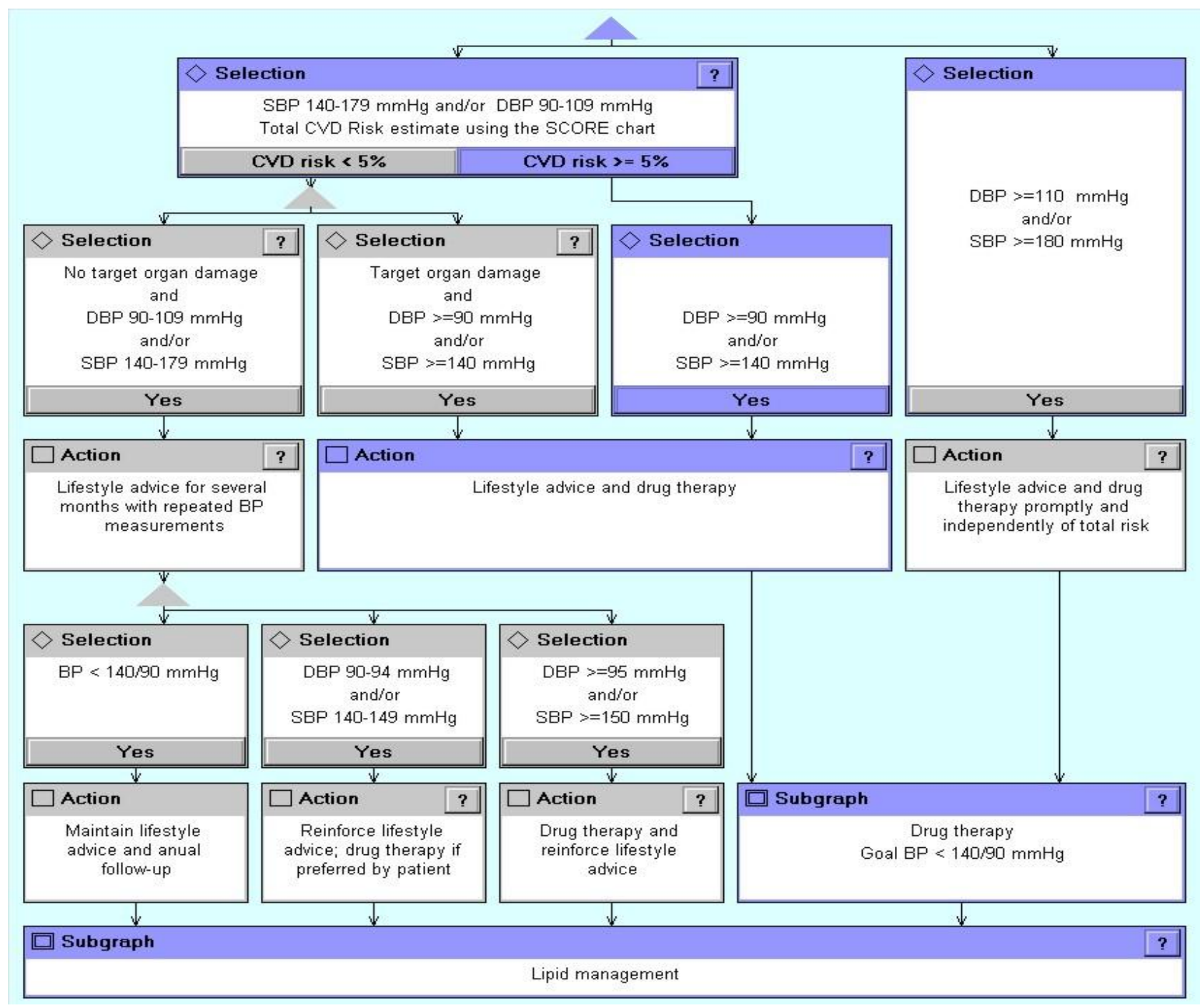

Fig. 1. Glifview example. 
Moreover, it can show both the basic information and the complete text of guidelines belonging to the selected GLIF model element. The Risk calculator system serves for calculation of a total cardiovascular risk from entered data of an individual patient (Figure 2).

Г Established CVD (CHD, peripheral artery disease, cerebrovascular atherosclerotic disease)

Presence of diabetes type 2 or diabetes type 1 with microalbuminuria

$\lceil$ LDL cholesterol $>=6 \mathrm{mmol} / /(240 \mathrm{mg} / \mathrm{dl})$ and $/$ or Total cholesterol $>=8 \mathrm{mmol} / /(320 \mathrm{mg} / \mathrm{dl})$

$\Gamma D_{B P}>=110 \mathrm{~mm} \mathrm{Hg}$ and $/ 0 \mathrm{SBP}>=180 \mathrm{~mm} \mathrm{Hg}$

\section{ГSmoker}

$\Gamma$ Low risk region (Belgium, France, Greece, Italy, Luxembourg, Spain, Switzerland, Portugal)

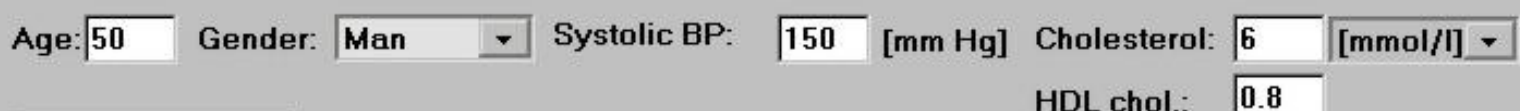

\section{Calculate}

Result

Risk of fatal CVD: 10 -year: $5 \%$. Projection to age 60 years: $13 \%$

Absolute risk of fatal CVD: $>=5 \%$
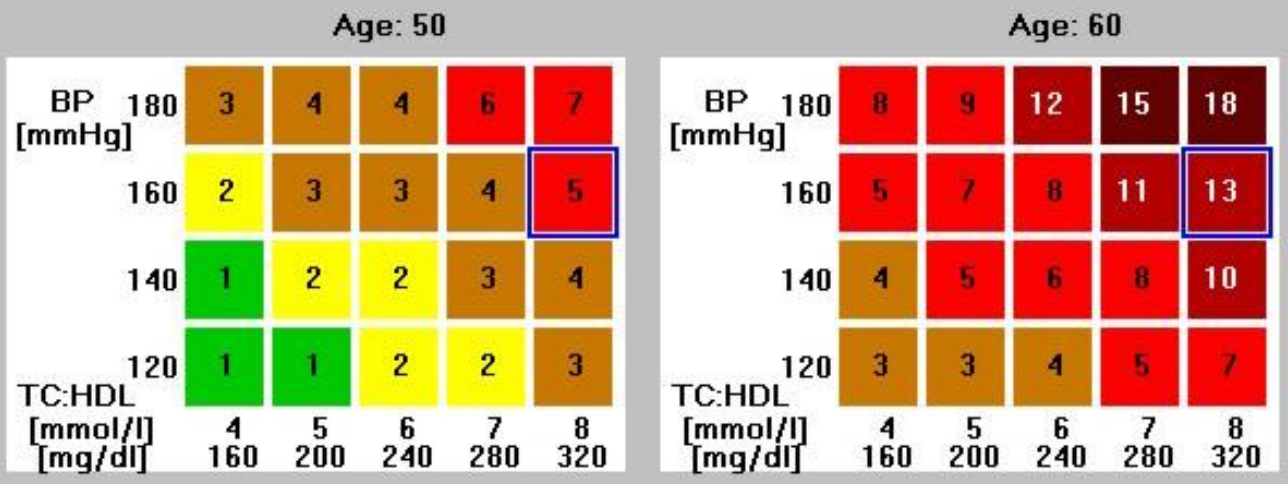

\begin{tabular}{|l|l|}
\hline Score \\
\hline$>15 \%$ \\
$10 \%-14 \%$ \\
$5 \%-9 \%$ \\
$3 \%-4 \%$ \\
$2 \%$ \\
$1 \%$ \\
$<1 \%$ \\
\hline
\end{tabular}

Fig. 2. Estimation of total cardiovascular disease risk - SCORE chart (high risk region).

Estimation of total cardiovascular risk determinates the term of starting the pharmacological therapy of hypertension and other risk factors. This decision could be speeded up by the preferential estimation of some variables as it is used in the educational system. These are associated clinical conditions, diabetes mellitus, items of target organ damage and extreme values of some risk factors. Each of them individually corresponds to a high cardiovascular risk, which indicates starting the pharmacological therapy. If one of such variables is present it is sufficient for the decision to start the pharmacological therapy itself and estimation of other risk factors is not at the moment necessary.

The Drugs selection system enables selection of a drug class according to its indications and contraindications.

The dynamic table compared to the static table of the classical paper HGL makes the drug selection much easier (Figure 3). It has an extra column with items in groups mainly according to body systems. Marking a certain item (e.g. heart failure) in this column is associated with automated marking of the same item in rows of several drug classes in the cells crossing both indication and contraindication columns.

An indicated drug class is highlighted in green; the contraindicated drug class is highlighted either in red (compelling) or yellow (possible). No colour is used when the drug class is neutral. The system shows also combined situations - a combination of an indication and contraindication within one drug class (Figure 3). 


\begin{tabular}{|c|c|c|c|}
\hline Class & Conditions favouring the use & Contraindications & $\begin{array}{l}\text { Selection list based mainly } \\
\text { on body systems }\end{array}$ \\
\hline $\begin{array}{l}\text { Diuretics } \\
\text { (thiazides) }\end{array}$ & $\begin{array}{l}\square \text { Congestive heart failure } \\
\square \text { Elderly hypertensnes } \\
\square \text { isolated systolic hypertension } \\
\square \text { Hypertensives of African origin }\end{array}$ & $\begin{array}{l}\triangle \text { Gout } \\
\square \text { Pregnancy }\end{array}$ & $\begin{array}{l}\text { Heart } \\
\square \text { A- } \vee \text { block (grade } 2 \text { or } 3 \text { ) } \\
\square \text { Angina pectoris } \\
\square \text { Congestive heart failure } \\
\square \text { Left ventricular hypertrophy }\end{array}$ \\
\hline $\begin{array}{l}\text { Diuretics } \\
\text { (loop) }\end{array}$ & $\begin{array}{l}\square \text { Renal insufficiency } \\
\square \text { Congestive heart failure }\end{array}$ & & $\begin{array}{l}\square \text { LV dysfunction } \\
\square \text { Post-myocardial infarction } \\
\square \text { Supraventricular tachycardia }\end{array}$ \\
\hline \multirow[t]{2}{*}{$\begin{array}{l}\text { Diuretics } \\
\text { (anti-aldosterone) }\end{array}$} & \multirow[t]{2}{*}{$\begin{array}{l}\bigotimes \text { Congestive heart failure } \\
\bigotimes \text { Post-myocardial infarction }\end{array}$} & \multirow[t]{2}{*}{$\begin{array}{l}\square \text { Renal failure } \\
\square \text { Hyperkalaemia }\end{array}$} & $\square$ Tachyarrhythmias \\
\hline & & & \multirow[b]{2}{*}{$\begin{array}{l}\text { Blood vessels } \\
\square \text { Bilateral renal artery stenosis } \\
\square \text { Carotid atherosclerosis } \\
\square \text { Isolated systolic hypertension } \\
\square \text { Orthostatic hypotension } \\
\square \text { Peripheral vascular disease }\end{array}$} \\
\hline \multirow[t]{2}{*}{ Beta-blockers } & \multirow[t]{2}{*}{$\begin{array}{l}\square \text { Angina pectoris } \\
\square \text { Post-myocardial infarction } \\
\triangle \text { Congestive heart failure * } \\
\text { (up-titration) } \\
\square \text { Pregnancy } \\
\square \text { Tachyarrhythmias }\end{array}$} & \multirow[t]{2}{*}{$\begin{array}{l}\square \text { Asthma } \\
\square \text { Chronic obstructive pulmonary d. } \\
\square \text { A.V block (grade } 2 \text { or } 3 \text { ) } \\
\square \text { Peripheral vascular disease } \\
\square \text { Glucose intolerance } \\
\square \text { Athletes and physically active }\end{array}$} & \\
\hline & & & \multirow[b]{2}{*}{$\begin{array}{l}\text { Kidney } \\
\square \text { Diabetic nephropathy } \\
\square \text { Diabetic microalbuminuria } \\
\square \text { Renal failure } \\
\square \text { Renal insufficiency } \\
\square \text { Non diabetic nephropathy } \\
\square \text { Type-1 diabetic nephropathy } \\
\square \text { Proteinuria }\end{array}$} \\
\hline $\begin{array}{l}\text { Calcium } \\
\text { antagonists } \\
\text { (dihydropyridines) }\end{array}$ & $\begin{array}{l}\square \text { Elderly hypertensives } \\
\square \text { Isolated systolic hypertension } \\
\square \text { Angina pectoris } \\
\square \text { Peripheral vascular disease } \\
\square \text { Carotid atherosclerosis } \\
\square \text { Pregnancy }\end{array}$ & $\begin{array}{l}\square \text { Tachyarrhythmias } \\
\square \text { Congestive heart failure }\end{array}$ & \\
\hline $\begin{array}{l}\text { Calcium } \\
\text { antagonists } \\
\text { (verapamil, } \\
\text { diltiazem) }\end{array}$ & $\begin{array}{l}\square \text { Angina pectoris } \\
\square \text { carotid atherosclerosis } \\
\square \text { Suprancentricular tachycardia }\end{array}$ & $\begin{array}{l}\square \text { A- } \vee \text { block (grade } 2 \text { or } 3 \text { ) } \\
\square \text { Congestiwe heart failure }\end{array}$ & $\begin{array}{l}\text { Lung } \\
\square \text { Asthma } \\
\square \text { Chronic obstructive pulmonary d. }\end{array}$ \\
\hline $\begin{array}{l}\text { Angiotensin- } \\
\text { converting enzyme } \\
\text { (ACE) } \\
\text { inhibitors }\end{array}$ & $\begin{array}{l}\square \text { Congestive heart failure } \\
\square \text { LV dysfunction } \\
\square \text { Post-myocardial infarction } \\
\square \text { Non diabetic nephropathy } \\
\square \text { Type-1 diabetic nephropathy } \\
\square \text { Proteinuria }\end{array}$ & $\begin{array}{l}\square \text { Pregnancy } \\
\square \text { Hyperkalaemia } \\
\square \text { Bilateral renal artery stenosis }\end{array}$ & $\begin{array}{l}\text { Metabolic disorders } \\
\square \text { Glucose intolerance } \\
\square \text { Gout } \\
\square \text { Hyperkalaemia } \\
\square \text { Hyperlipidaemia }\end{array}$ \\
\hline $\begin{array}{l}\text { Angiotensin II } \\
\text { receptor antagonists } \\
\text { (AT1-blockers) }\end{array}$ & $\begin{array}{l}\square \text { Diabetic nephropathy } \\
\square \text { Diabetic microalbuminuria } \\
\square \text { Proteinuria } \\
\square \text { Left ventricular hypertrophy } \\
\square \text { ACE-inhibitor cough }\end{array}$ & $\begin{array}{l}\square \text { Pregnancy } \\
\square \text { Hyperkalaemia } \\
\square \text { Bilateral renal artery stenosis }\end{array}$ & $\begin{array}{l}\text { Various special conditions } \\
\square \text { ACE-inhibitor cough } \\
\square \text { Athletes and physically active } \\
\square \text { Hypertensives of African origin } \\
\square \text { Elderly hypertensives } \\
\square \text { Monotherapy? } \\
\square \text { Pregnancy }\end{array}$ \\
\hline \multirow[t]{2}{*}{ Alfa-blockers } & \multirow[t]{2}{*}{$\begin{array}{l}\square \text { Prostatic hyperplasia }(\mathrm{BPH}) \\
\square \text { Hyperlipidaemia }\end{array}$} & \multirow{2}{*}{$\begin{array}{l}\square \text { Orthostatic hypotension } \\
\square \text { Congestive heart failure } \\
\square \text { Monotherapy? } \\
\text { (less suitable for monotherapy) }\end{array}$} & $\square$ Prostatic hyperplasia (BPH) \\
\hline & & & $\begin{array}{l}\text { Explanation } \\
\text { Indications } \\
\text { Possible contraindications } \\
\text { Compelling contraindications }\end{array}$ \\
\hline
\end{tabular}

\begin{tabular}{|l|l|}
\hline \multicolumn{2}{|c|}{$\begin{array}{c}\text { The most rational combinaton therapy } \\
\text { Drug class 1 } \\
\text { Drug class 2 }\end{array}$} \\
\hline Diuretics (loop) & Beta-blockers \\
\hline Diuretics (anti-aldosterone) & Beta-blockers \\
\hline Diuretics (loop) & ACE inhibitors \\
\hline Diuretics (loop) & AT1-blockers \\
\hline Diuretics (loop) & Calcium antagonists (dihydropyridines) \\
\hline Diuretics (anti-aldosterone) & Calcium antagonists (dihydropyridines) \\
\hline Beta-blockers & Calcium antagonists (dihydropyridines) \\
\hline Beta-blockers & Alfa-blockers \\
\hline Calcium antagonists (dihydropyridines) & ACE inhibitors \\
\hline Calcium antagonists (dihydropyridines) & AT1-blockers \\
\hline ACE inhibitors & Alfa-blockers \\
\hline
\end{tabular}

Fig. 3. Indications and contraindications for the major classes of antihypertensive drugs and their combinations. 
Moreover, a physician can differentiate between indicated drug classes according to the number of indicative items when there are more drug classes indicated. This is also beneficial from educational point of view.

Similarly, in a drug class selection, the estimated compelling contraindication (to a lesser degree also the possible contraindication) disqualifies the drug class from using in the individual patient. For optimal drug combination only those drugs are suitable, which are indicated both for monotherapy and effectiveness of their combination (Figure 3 at the bottom).

The obstacle to a practical use of such decision support systems is the repeated input of patients' data. This can be prevented by retrieving data directly from a structured electronic health record (EHR). Therefore, the pilot testing of the formalized HGL for research purposes was realized in cooperation with two Czech companies producing hospital information systems. Thus we had the chance to know the way of collecting data in their systems. Data were mostly in a free, not structured text, which disabled their automatic extraction into the formalized GL.

A sufficiently structured electronic health record would be needed for this purpose containing all the variables used in GL for decisionmaking. Moreover, values of the variables would have to be expressed in an appropriate form, e.g. diagnoses in codes of International Statistical Classification of Diseases and Related Health Problems, Tenth Revision, defined conclusions of some examinations etc.

Therefore, meanwhile an alternative version of processing HGL was created and a physician can put patient's data directly in the website version on http://guidelines.euromise.cz/). There is a list of all the variables used the values of which are to be filled in by a physician shown at the left part of Figure 4. Compared to the educational system the browser goes automatically through the GLIF model graph evaluating conditions of decision steps. If some condition could not be evaluated, as the needed data items are not available, the browser stops and highlights the branch from the root to the current step. Thus it can serve as a reminder of missing data necessary for the correct decision. Then the user can input missing data manually (or simulate data) to the browser to continue in visualization.



Fig. 4. Processing version of GL. 
Both qualitative and quantitative variables are used in $\mathrm{GL}$ for decision-making. The continuous quantitative variables are also presented as categorical due to the arbitrary given limits between normal and pathological states (blood pressure - BP, cholesterol or creatinine concentration, left ventricle hypertrophy according to ECG or echocardiography).

The presence or absence of a pathological state (yes-no) in a certain variable has to be expressed for the correct decision-making. In practice the third possibility occurs frequently that a variable value was not estimated yet or is less probable that it will be estimated at all due to financial or other reasons (not available).

The processing version of GL solves the problem of the three-value logic with a missing value that the browser stops and highlights the branch from the root to the current step. Thus it can serve as a reminder of missing data necessary for the correct decision.

Then a physician can manually simulate both variants of the decision algorithm and evaluate their risks for a real decision in an individual patient or input the missing value.

In case of a low or medium added cardiovascular risk based only on accessible data it is essential to complete the majority of missing items, it means only the results of examinations that are performed without clinical suspicion can miss.

The processing GL system also solves problems associated with a transformation of a static flow chart or pure text of paper GL in a system providing the decision algorithm repeatedly as during repeated patient visits with already started pharmacological therapy with possible quantitative (lowering of BP due to a therapy) and qualitative (recently estimated target organ damage, associated clinical condition or diabetes with possible consequent change of goal BP value) changes which can modify a patient's total CVD risk and conditions for drug class selection.

The system gives a short explanation of appropriate decision step by means of a summary of used items - shown at the left bottom part of Figure 4. This is an important property of the system to keep its educative function and prevent its degradation to a cybernetic "black box" with putting data on one side and receiving a recommendation on the other side.

All the possibilities used in decision algorithm could be expressed by means of formalization steps as we could check during formalization of several medical GL in cardiology - 1999 WHO/ISH Hypertension Guidelines, HGL, CDPGL, Czech GL for treatment of atrial fibrillation, Czech GL for management of pulmonary arterial hypertension and Czech GL for treatment of unstable angina pectoris in cooperation with the Czech Society of Cardiology.

In a stage of GLIF model construction from text guidelines, it is important to find a logical and process structure of guidelines, all fundamental parameters and their interrelationships.

Cooperation of an expert in informatics and medical specialist, preferably one of the authors of text guidelines was especially effective. Thus uncertainties and information inconsistencies in their free texts, which were not found out, by opponents and medical public could be explained and removed. The Czech Society of Cardiology is interested in its each new GL checking by means of formalization before its classical publication.

In future the system could offer the possibility of keeping data and selected steps of the GLIF model which were used for decision, possibly with a graphical follow up of selected variables - modifiable risk factors.

Future research will probably bring a development of general module, which could be connected using a suitable interface to a sufficiently structured information system in hospital and physician's office using international standards.

\section{Conclusions}

Formalization of guidelines by means of general GLIF model presents a suitable additional educational tool for their easier knowledge implementation in comparison with the classical paper form.

- It offers to physicians a system for a decision support and it checks their decision algorithms in comparison with those of guidelines.

- It could serve as a tool for an audit of physicians' work by their professional society.

\section{Acknowledgement}

Supported by the project 1ET200300413 AS CR and institutional research plan of ICS AS CR AV0Z10300504. 


\section{References}

[1] De Backer. et al.: European Guidelines on Cardiovascular Disease Prevention in Clinical Practice: Journal of Cardiovascular Prevention and Rehabilitation 2003, 10 (Suppl. 1): pp. S1-S78

Peleska J., Anger Z., Buchtela D., Tomeckova M., Vesely A., Zvarova J.: Formalized 2003 European Guidelines on Cardiovascular Disease Prevention in Clinical Practice. In: European Heart Journal. Journal of the European Society of Cardiology, Vol.25 Abstract

[2] Supplement, August / September 2004. ESC Congress 2004, 28.8.-1.9. Munich, Germany. (Eds: Stefan Janssens, Frank Rademakers), European Society of Cardiology, 2004, pp. 444-444, ISSN: 0195-668X

[3] Guidelines Committee: 2003 European Society of Hypertension-European Society of Cardiology guidelines for the management of arterial hypertension. J. Hypertens., 21, 2003; 6: 1011-1053

[4] Ohno-Machado L., Gennaril, J. H., Murphy S. N., Jain N. L., Tu S. W., Oliverd D. et al.: The GuideLine Interchange Format: A model for representing guidelines, Journal of the American Medical Informatics Association 1998, 5 (4), pp. 357-372.

Zvarova J., Vesely A., Hanzlicek P., Spidlen J., Buchtela D.: On Direct Comparing of Medical Guidelines with Electronic Health

[5] Record. In: Computational Science - ICCS 2004. 4th International Conference Kraków, Poland, June 6-9, 2004 Proceedings, Part IV (Eds: Jack J. Dongarra), Springer-Verlag Berlin, 2004, pp. 1133-1139

[6] Buchtela D., Peleska J., Vesely A., Zvarova J.: Presentation of Medical Guidelines on a Computer, Transformation of Healthcare with

[6] Information Technologies, Ed.: Zielinski K., Duplaga M., Ingram D., IOS Press, Amsterdam, 2004, pp.166-171, ISBN 1-58603-438-3 